\title{
Mechanism of Positive Allosteric Modulators Acting on AMPA Receptors
}

\author{
Rongsheng Jin, ${ }^{1}$ Suzanne Clark, ${ }^{4}$ Autumn M. Weeks, ${ }^{4}$ Joshua T. Dudman, ${ }^{2}$ Eric Gouaux, ${ }^{1,3}$ and Kathryn M. Partin ${ }^{4}$ \\ ${ }^{1}$ Department of Biochemistry and Molecular Biophysics, ${ }^{2}$ Center for Neurobiology and Behavior, and ${ }^{3}$ Howard Hughes Medical Institute, Columbia \\ University, New York, New York 10032, and ${ }^{4}$ Department of Biomedical Sciences, Division of Neuroscience, Colorado State University, Fort Collins, \\ Colorado 80523
}

Ligand-gated ion channels involved in the modulation of synaptic strength are the AMPA, kainate, and NMDA glutamate receptors. Small molecules that potentiate AMPA receptor currents relieve cognitive deficits caused by neurodegenerative diseases such as Alzheimer's disease and show promise in the treatment of depression. Previously, there has been limited understanding of the molecular mechanism of action for AMPA receptor potentiators. Here we present cocrystal structures of the glutamate receptor GluR2 S1S2 ligand-binding domain in complex with aniracetam [1-(4-methoxybenzoyl)-2-pyrrolidinone] or CX614 (pyrrolidino-1,3-oxazino benzo-1,4-dioxan-10one), two AMPA receptor potentiators that preferentially slow AMPA receptor deactivation. Both potentiators bind within the dimer interface of the nondesensitized receptor at a common site located on the twofold axis of molecular symmetry. Importantly, the potentiator binding site is adjacent to the "hinge" in the ligand-binding core "clamshell" that undergoes conformational rearrangement after glutamate binding. Using rapid solution exchange, patch-clamp electrophysiology experiments, we show that point mutations of residues that interact with potentiators in the cocrystal disrupt potentiator function. We suggest that the potentiators slow deactivation by stabilizing the clamshell in its closed-cleft, glutamate-bound conformation.

Key words: glutamate receptor; desensitization; deactivation; kinetics; crystallography; cyclothiazide; aniracetam; CX614

\section{Introduction}

At the cellular level, short- and long-term memory storage involves the strengthening and weakening of synapses (Kandel, 2001). Key molecules located at chemical synapses are ionotropic glutamate receptors (iGluRs), ligand-gated ion channels that mediate the majority of fast-synaptic signal transduction in the mammalian brain (Dingledine et al., 1999). Experiments in transgenic mice (Tsien et al., 1996), as well as pharmacological studies in rodents and humans (Morris et al., 1986; Rammsayer, 2001), underscore the importance of AMPA- and NMDAsensitive iGluRs in learning and memory. In fact, positive allosteric modulators that slow deactivation of AMPA receptors improve short-term memory in humans (Ingvar et al., 1997) and

\footnotetext{
Received June 22, 2005; revised Aug. 12, 2005; accepted Aug. 16, 2005.

This work was supported by the National Institutes of Health (K.M.P., E.G.) and the American Heart Association (K.M.P.), and E.G. is an investigator with the Howard Hughes Medical Institute. J.T.D. was supported by a National Science Foundation Graduate Research Fellowship. Diffraction data sets were collected at beam lines X4A at the National Synchrotron Radiation Source with the assistance of C. Ogata, R. Abramowitz, and X. Yang. R. Olsen performed the sedimentation equilibrium experiments using an XL-I centrifuge purchased using funds provided by the National Institutes of Health. We thank G. Rogers for providing CX614. K.M.P. thanks K. Beam for insightful scientific discussions.

Correspondence should be addressed to either of the following: Dr. Eric Gouaux, Howard Hughes Medical Institute/Vollum Institute, Oregon Health and Sciences University, Portland, OR 97239, E-mail: gouauxe@ohsu.edu; or Dr. Kathryn M. Partin, Department of Biomedical Sciences, Division of Neuroscience, 200 West Lake Street, Colorado State University, Fort Collins, C0 80523, E-mail: kpartin@lamar.colostate.edu.

R. Jin's present address: Howard Hughes Medical Institute, Stanford University, James H. Clark Center, E300, 318 Campus Drive, Stanford, CA 94305

DOI:10.1523/JNEUROSCI.2567-05.2005

Copyright $\odot 2005$ Society for Neuroscience $\quad 0270-6474 / 05 / 259027-10 \$ 15.00 / 0$
}

may also prove useful for the treatment of depression and other disorders and diseases of the nervous system (O'Neill et al., 2004).

In studies using recombinant receptors and rapid perfusion, patch-clamp electrophysiology experiments, positive allosteric modulators such as aniracetam [1-(4-methoxybenzoyl)-2pyrrolidinone] (Ani) and CX614 (pyrrolidino-1,3-oxazino benzo-1,4-dioxan-10-one) (CX) slow deactivation of AMPA receptors, or the rate at which the ion channel closes after the removal of glutamate (Vyklicky et al., 1991; Partin et al., 1996; Arai et al., 2000; Lawrence et al., 2003). However, aniracetam, CX614, and $\quad \mathrm{N}$-2-[4-(4-cyanophenyl)phenyl]propyl 2-propanesulfonamide (LY404187), as well as other related positive allosteric modulators (Miu et al., 2001; Quirk and Nisenbaum, 2003), also slow desensitization, a process by which the receptor ion channel closes although glutamate remains tightly bound (Isaacson and Nicoll, 1991; Tang et al., 1991; Arai et al., 2000; Sun et al., 2002). On the basis of experiments in rodents and humans, the cognitive enhancing properties of therapeutic agents such as aniracetam and CX614 are primarily attributable to their slowing of deactivation (Arai and Lynch, 1998). Therefore, it is of substantial interest to determine how positive modulators slow deactivation.

At the present time, there is no information, at the level of molecular detail, on how small molecules modulate the deactivation kinetics of any ligand-gated ion channel, although we have recently learned a great deal about how small molecules and specific mutations such as cyclothiazide and the leucine 483 to tyrosine mutation slow desensitization of AMPA receptors, respectively (Sun et al., 2002; Fleck et al., 2003; Leever et al., 2003; 
Horning and Mayer, 2004). Because modulators of desensitization act at the interface between glutamate binding subunits of AMPA receptors, we reasoned that molecules that slowed deactivation might also bind in the context of the glutamate binding domains. To map the binding site(s) and determine the mechanism by which aniracetam and CX614 modulate deactivation in AMPA receptors, we have determined the cocrystal structures of the GluR2 ligand-binding core in complex with the modulators, and we have tested specific receptor-modulator interactions using site-directed mutagenesis and rapid perfusion, patch-clamp electrophysiology experiments.

\section{Materials and Methods}

Materials. Aniracetam, L-quisqualic acid (Quis), and NBQX were obtained from Tocris Bioscience (Ellisville, $\mathrm{MO}$ ), kynurenic acid was from Sigma (St. Louis, MO), cyclothiazide (CTZ) was from Alexis Biochemicals (San Diego, CA), and CX614 was generously provided by Cortex Pharmaceuticals (Irvine, CA). The rat GluR2 S1S2J construct used in this study was derived from GluR2 flop (Boulter et al., 1990; Keinänen et al., 1990) and has been described previously (Armstrong and Gouaux, 2000). Protein expression, refolding, and purification were performed using previously described methods (Chen and Gouaux, 1997). Before crystallization, glutamate was removed by dialyzing the GluR2 S1S2J protein extensively against a buffer composed of $10 \mathrm{mM}$ HEPES, pH 7.0, $20 \mathrm{~mm}$ $\mathrm{NaCl}$, and $1 \mathrm{~mm}$ EDTA, and the protein was concentrated to $\sim 10 \mathrm{mg} / \mathrm{ml}$ (calculated $\epsilon_{280}$ of $39,640 \mathrm{M}^{-1} \mathrm{~cm}^{-1}$ ).

Crystallization and measurement of diffraction data. Before crystallization, the following ligands were added to the protein solution (final concentrations): $5 \mathrm{~mm}$ fluorowillardiine and $10 \mathrm{~mm}$ aniracetam, or $5 \mathrm{~mm}$ quisqualate and $5 \mathrm{~mm} \mathrm{CX614.} \mathrm{Crystals} \mathrm{were} \mathrm{grown} \mathrm{at} 4^{\circ} \mathrm{C}$ by vapor diffusion, and each drop contained a 1:1 ratio of protein and reservoir solution. The reservoir solution for the aniracetam complex was $12-14 \%$ polyethylene glycol (PEG) $8000,0.25-0.35 \mathrm{M}$ ammonium sulfate, and 0.1 M sodium citrate, $\mathrm{pH}$ 5.5-6.0; the CX614 crystals were obtained from a reservoir solution composed of $10-14 \%$ PEG $8000,0.1-0.15 \mathrm{M}$ zinc acetate, and $0.1 \mathrm{M}$ sodium acetate, $\mathrm{pH} 5.5$.

Crystals were soaked in corresponding crystallization buffers supplemented with ligands and 12-16\% glycerol before flash cooling in liquid nitrogen. Both data sets were collected at $110 \mathrm{~K}$ at the NSLS X4A beam line. The diffraction data were processed with the HKL suite of programs. The CX614 cocrystals belonged to the $\mathrm{P} 2{ }_{1} 2{ }_{1} 2$ space group, and the cell was isomorphous to the zinc crystal form of the previously described quisqualate complex (Jin et al., 2002). The aniracetam cocrystals also belonged to the $\mathrm{P}_{1}{ }_{1} 22$ space group. However, the symmetry for both cocrystals was reduced to $\mathrm{P} 2$ to facilitate crystallographic refinement of the complex because, in the $\mathrm{P} 2{ }_{1} 2{ }_{1} 2$ space group, CX614 or aniracetam was positioned on the crystallographic twofold axis.

Structure determination. The structure of the CX614/Quis complex was solved by difference Fourier techniques using phases calculated from the "zinc form" quisqualate structure (Jin et al., 2002). The Ani/fluorowillardiine (FW) complex structure was solved by molecular replacement using AmoRe (Navaza, 1994) using the FW complex structure without solvent molecules and ligand as a search model (Jin and Gouaux, 2003). Crystallographic refinements were performed with CNS (Brünger et al., 1998), and the program O was used for model building (Jones et al., 1991; Jones and Kjeldgaard, 1997). Strong noncrystallographic symmetry restraints (weight of 300) were applied to the six protomers in the CX614/ Quis structure and the two protomers in the Ani/FW structure. Refinements were begun with rigid body minimization followed by a slow-cool, simulated-annealing protocol at $5000 \mathrm{~K}$ to reduce model bias, followed by iterative rounds of positional and individual B-factor refinement and manual model building into omit maps until the $R_{\text {free }}$ value converged (Brünger, 1992). The crystal structure of aniracetam was obtained from the Cambridge Structural Database under entry code GIJVOK. The CX614 structure was constructed based on two small molecule crystal structures with codes of VIGFUM and GODWAX, and the resulting structure was subjected to energy minimization using PRODRG (van Aalten et al., 1996). Because the modulators bind on the molecular two- fold axis, two modulator molecules were modeled for each binding site, each with occupancies of 0.5 and related by a noncrystallographic twofold axis. Least squares superpositions were calculated using LSQMAN (Kleywegt, 1999), and the extent of domain closure was determined using the program FIT (http://bioinfol.mbfys.lu.SE/ guoguang/fit.html). The degree of domain closure was defined as the rotation required to fit in domain 2 (Ile 500-Lys 506; Pro 632-Asp 728; Gly-Thr linker) after superposition of $\alpha$-carbon atoms in domain 1 (Val 395-Phe 495; Tyr 732-Tyr 768). MOLSCRIPT (Kraulis, 1991), BOBSCRIPT (Esnouf, 1999), Raster3D (Merritt and Murphy, 1994), and Pymol (Delano, 2005) were used to make the figures. Coordinates for the aniracetam and CX614 complexes have been deposited in the Protein Data Bank under accession numbers of 2AL5 and 2AL4, respectively.

Sedimentation equilibrium. Sedimentation equilibrium ultracentrifugation runs were performed in a Beckman Instruments (Fullerton, CA) XL-I analytical ultracentrifuge. The experimental setup and data analyses were performed as described previously (Sun et al., 2002). Purified GluR2 S1S2J samples at $\sim 1.2 \mathrm{mg} / \mathrm{ml}$ were first dialyzed extensively against buffer A, which was composed of $20 \mathrm{~mm}$ Tris- $\mathrm{HCl}, \mathrm{pH} 7.5,200$ $\mathrm{mm} \mathrm{NaCl}$, and $1 \mathrm{~mm}$ EDTA. For the three experiments presented in this study, the protein samples were finally dialyzed overnight against buffer A supplemented with the following: (1) $2 \mathrm{~mm}$ glutamate and $5 \mathrm{~mm}$ aniracetam; (2) $0.3 \mathrm{~mm}$ AMPA and $0.3 \mathrm{~mm}$ CX614; or (3) $0.3 \mathrm{~mm}$ CX614. We were unable to examine the effects of higher concentrations of aniracetam because of its limited solubility. These last dialysis buffers were used as the blank controls, and the data were measured using interference optics. The sedimentation equilibrium experiments were performed using three different loading concentrations of protein $(0.75,0.5$, and $0.25 \mathrm{mg} / \mathrm{ml}$ for the aniracetam sample and $1.0,0.75$, and $0.4 \mathrm{mg} / \mathrm{ml}$ for the CX614 samples) and three different speeds (15,000, 20,000, and $27,000 \mathrm{rpm}$ ). All dialyses and sedimentation equilibrium experiments were performed at $4^{\circ} \mathrm{C}$.

Transient transfections. Human embryonic kidney 293 (HEK 293) fibroblasts (CRL 1573; American Type Culture Collection, Rockville, MD) were cultured as described previously (Partin et al., 1996). Cells were transiently transfected using FuGene 6 reagent (Roche Products, Indianapolis, IN) with GluR2 cDNA and enhanced green fluorescent protein cDNA (0.5-2 and 0.1-0.15 $\mu \mathrm{g} / 35 \mathrm{~mm}$ dish, respectively). After transfection, NBQX $(10 \mu \mathrm{M})$ and kynurenic acid $(1 \mathrm{~mm})$ were added to the media.

Outside-out patch recordings. Currents were recorded 2-4 d after transfection, as described previously (Leever et al., 2003). Extracellular solutions (ECS) contained the following: $20 \mathrm{~mm}$ sucrose, $145 \mathrm{~mm} \mathrm{NaCl}$, $5.4 \mathrm{~mm} \mathrm{KCl}, 5 \mathrm{~mm}$ HEPES, $1 \mathrm{~mm} \mathrm{MgCl}_{2}, 1.8 \mathrm{~mm} \mathrm{CaCl}_{2} \cdot \mathrm{H}_{2} \mathrm{O}$, and 0.01 $\mathrm{mg} / \mathrm{ml}$ phenol red, $\mathrm{pH}$ 7.3. To protect cells from excessive bath exposure to agonists and modulators, ECS also contained NBQX ( $3 \mu \mathrm{M})$ with or without kynurenic acid (1 mM) or lowered calcium concentrations, and bath solutions were fully exchanged after drug exposures. Outside-out membrane patches were voltage clamped at $-60 \mathrm{mV}$ using an Axopatch 200B amplifier (Molecular Devices, Union City, CA). Synapse (version 3.6d; Synergy Research, Silver Spring, MD) controlled piezoelectric movement, data acquisition, and trace analysis. Responses were filtered at $5 \mathrm{kHz}$, digitized at $10-500 \mu \mathrm{s} /$ point, and stored on a Power Macintosh computer (Apple Computers, Cupertino, CA) using an ITC-16 interface (InstruTech, Port Washington, NY). Micropipettes (TW150F; 2-5 M $\Omega$; World Precision Instruments, Sarasota, FL) contained the following (in $\mathrm{mm}$ ): $135 \mathrm{CsCl}, 10 \mathrm{CsF}, 10 \mathrm{HEPES}, 5 \mathrm{Cs}-\mathrm{BAPTA}, 1 \mathrm{MgCl}_{2}$, and $0.5 \mathrm{CaCl}_{2}$, $\mathrm{pH} 7.2(292 \mathrm{mOsm})$. Patches were perfused at $0.3 \mathrm{ml} / \mathrm{min}$ with solutions emitted from a two-barrel flow pipe made with $\theta$ tubing (BT150-10; Sutter Instruments, Novato, CA). For baseline agonist responses, one barrel contained vehicle control (control) composed of the following: $145 \mathrm{~mm} \mathrm{NaCl}, 5.4 \mathrm{~mm} \mathrm{KCl}, 5 \mathrm{~mm}$ HEPES, $1 \mathrm{~mm} \mathrm{MgCl}_{2}, 1.8 \mathrm{~mm}$ $\mathrm{CaCl}_{2} \cdot \mathrm{H}_{2} \mathrm{O}$, with $1 \%$ DMSO and $0.01 \mathrm{mg} / \mathrm{ml}$ phenol red, $\mathrm{pH}$ 7.3. The other barrel had this solution plus Quis ( $3 \mathrm{~mm}$ ). The flow pipe solutions used for testing CX were as above, only with CX614 (100 $\mu \mathrm{M})$ added to both barrels (i.e., CX-control and CX+Quis). Similar configurations were used for aniracetam and CTZ. After going into voltage clamp, an outside-out patch was pulled, lifted up to the flow pipe, positioned near the interface between the Quis-free and Quis-containing solutions, and jumped rapidly from the vehicle control into Quis or from CX-control 
A

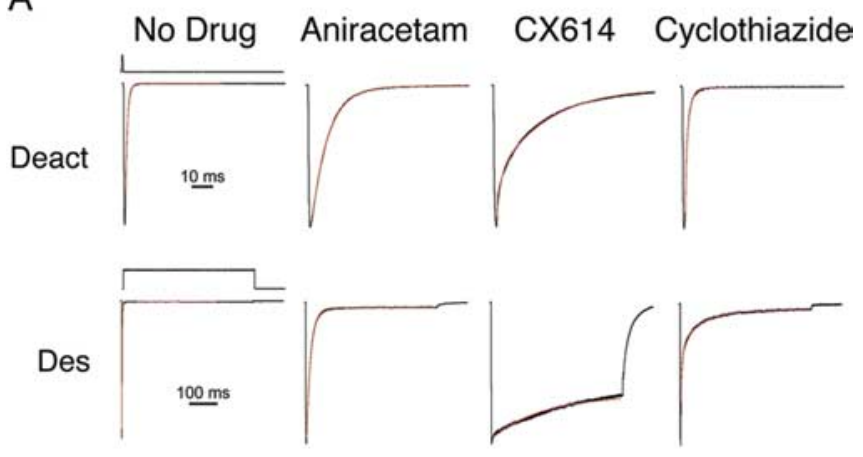

B

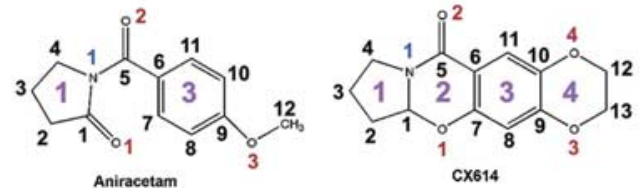

Figure 1. The positive allosteric modulators aniracetam and CX614 slow deactivation more profoundly than cyclothiazide at GluR2 (flop) receptors. $\boldsymbol{A}$, Electrophysiological responses of GluR2 (flop) expressed on outside-out patches of transiently transfected HEK 293 cells. Top traces show the kinetics of deactivation, the decay of the peak response after a brief ( $1 \mathrm{~ms}$ ) pulse of $3 \mathrm{~mm}$ quisqualate. Bottom traces show the kinetics of desensitization, the decay during a prolonged ( $500 \mathrm{~ms}$ ) pulse of quisqualate. Responses are shown for patches with no drug or with 5 mm aniracetam, $100 \mu \mathrm{m}$ CX614, or $100 \mu \mathrm{m}$ cyclothiazide. Single-exponential fits are superimposed on the trace. Open-tip potentials are shown above the control traces. Note that desensitization by CTZ of GluR20 is only partially modulated compared with the flip isoform in which desensitization is virtually blocked. $\boldsymbol{B}$, Chemical structures of aniracetam and CX614. The atoms of aniracetam and CX614 are numbered using smaller font, with oxygen atoms in red and carbon atoms in black, and the rings are numbered using a larger font.

into CX+Quis. Rapid solution exchanges of 1 or 500 ms were driven by a piezoelectric device (Burleigh Instruments, Fishers, NY). Solution exchange rates were determined at the end of each experiment by open-tip junction currents and excluded if rise times exceeded $0.5 \mathrm{~ms}$.

Analysis of rapid responses. Deactivation rates were estimated by fitting a single exponential $\left(\tau_{\text {deact }}\right)$ to the $1 \mathrm{~ms}$ response decay; desensitization rates were estimated by fitting a single- or double-exponential function $\left(\tau_{\text {des }}\right)$ to the $500 \mathrm{~ms}$ response decay (from $95 \%$ of peak to steady state). Because modulators were slowly reversible, only cells naive to modulator were used for baseline Quis applications. Three to 20 responses per patch were averaged for analysis. Current traces and graphs were plotted using KaleidaGraph 3.5 (Synergy Software, Reading, PA).

Table 1.X-ray diffraction data collection statistics

\begin{tabular}{lll}
\hline & Aniracetam $^{a}$ & CX614 $^{a}$ \\
\hline Space group & $\mathrm{P} 2_{1}$ & $\mathrm{P} 2_{1}$ \\
Unit cell dimensions $(\AA)$ & $a=48.1, b=64.1, c=108.0 ; \beta=90.1^{\circ}$ & $a=114.3, b=163.7, c=47.3 ; \beta=90.0^{\circ}$ \\
\# Molecules per A.U. ${ }^{b}$ & 2 & 6 \\
Wavelength $(\lambda, \AA)(\AA)$ & 0.9763 & 0.9795 \\
$d_{\text {min }}(\AA)^{c}$ & $1.65(1.75)$ & $1.70(1.76)$ \\
Mean redundancy & 2.8 & 2.5 \\
$R_{\text {merge }}(\%)^{d, e}$ & $5.4(37.4)$ & $7.2(14.8)$ \\
Completeness $^{e}$ & $84.7(66.1)$ & $89.8(52.1)$ \\
\hline
\end{tabular}

${ }^{a}$ Aniracetam was cocrystallized with fluorowillardiine, whereas CX614 was cocrystallized with quisqualate.

${ }^{b}$ Number of protein molecules per asymmetric unit (A.U.).

Values in parentheses define the low-resolution limits for the highest-resolution shell of data.

${ }^{d} R_{\text {merge }}=\left(\Sigma\left|I_{i}-<I_{i}>\right|\right) / \Sigma\left|l_{i}\right|$, where $<I_{i}>$ is the mean $I_{i}$ over all symmetry-equivalent reflections.

${ }^{e}$ Values in parentheses are the statistics for the highest-resolution shell of data.

\section{Table 2. Refinement statistics}

\begin{tabular}{|c|c|c|}
\hline & Aniracetam & CX614 \\
\hline Resolution $(\AA)$ & $30.0-1.65$ & $30.0-1.70$ \\
\hline$R_{\text {work }}(\%)^{a}$ & 19.9 & 20.9 \\
\hline$R_{\text {free }}(\%)^{b}$ & 22.1 & 22.3 \\
\hline \# Protein atoms & 4024 & 11776 \\
\hline \# Water molecules & 711 & 776 \\
\hline \# Ligand atoms & 62 & 196 \\
\hline Mean $B$ value $\left(\AA^{2}\right)$ & 18.3 & 19.2 \\
\hline rms deviations from ideality: bonds/angles $\left(\AA /{ }^{\circ}\right)$ & $0.005 / 1.22$ & $0.005 / 1.20$ \\
\hline \multicolumn{3}{|c|}{$\begin{array}{l}{ }^{a} R_{\text {work }}=\left(\Sigma|| F_{0}|-| F_{\mathrm{c}} \mid\right) / \Sigma\left|F_{0}\right| \text {, where } F_{0} \text { and } F_{c} \text { denote observed and calculated structure factors, respectively. } \\
{ }^{b} \text { Ten percent of the reflections were set aside for calculation of } R_{\text {free }} \text {. }\end{array}$} \\
\hline
\end{tabular}

\section{Results}

\section{Modulation of deactivation}

Deactivation is the process by which the ion-conducting pore of glutamate receptors closes, allowing agonist to dissociate from the ligand-binding "clamshell." Deactivation is measured experimentally by exposing the receptor to such brief $(1 \mathrm{~ms})$ pulses of agonist that little receptor desensitization can occur. Desensitization is a long-lasting, agonist-bound, nonconducting state; it is measured experimentally by exposing the receptor to a prolonged $(500 \mathrm{~ms})$ pulse of agonist. CTZ prevents normal channel desensitization, the rearrangement of a dimer interface formed by adjacent subunits within a receptor complex that allows the ionconducting pore to close in the continued presence of agonist (Sun et al., 2002). CTZ modulates desensitization to a far greater extent than it does deactivation, and it is more efficacious on flip isoforms. Unlike CTZ, aniracetam and CX614 slow channel deactivation (Fig. 1) and are selective for flop rather than flip splice isoforms. Modulators of deactivation can have little (aniracetam) or marked (CX614) additional effects on desensitization.

\section{Structures of Ani/FW and CX/Quis complexes}

To define the location of the modulator binding sites, we solved cocrystal structures of the GluR2 S1S2 ligand-binding core complex with Ani/FW and CX/Quis at 1.65 and $1.7 \AA$ resolution, respectively. We used fluorowillardiine in the crystallographic studies with aniracetam because the Ani/FW complex diffracted to higher resolution than any of the other agonist-bound aniracetam complexes. Shown in Tables 1 and 2 are relevant crystallographic statistics. The Ani/FW and CX/Quis GluR2 S1S2 complexes crystallize as dimers with the same dimer interface as described previously (Armstrong and Gouaux, 2000; Sun et al., 2002; Mayer and Armstrong, 2004). There is a small but significant difference in the degree of domain closure in each protomeric clamshell: the Ani/FW and CX/Quis complexes are more closed by $\sim 1^{\circ}$ compared with the parent FW and Quis structures (Jin et al., 2002, 2003; Jin and Gouaux, 2003); however, the modulators do not produce any significant changes of binding site residues or water molecules within the agonist binding pockets.

Both modulators bind within the dimer interface of the nondesensitized conformation of the GluR2 S1S2 dimer (Sun et al., 2002); shown in Figure 2 are the electron densities associated with aniracetam and CX614. Strikingly, both modulators 
occupy a single site, located on the molecular twofold axis that relates one protein subunit to another, as illustrated in Figure 3. Because the modulators bind on the molecular twofold axis, their respective electron densities are superpositions of the electron densities of the modulators bound in twofold disordered orientations, each with occupancies of 0.5 . Despite this disorder, we were able to fit either orientation of aniracetam and CX614 to their associated electron densities because the crystals of the complexes diffract to high resolution and the maps have substantial atomic detail. In the crystallographic refinement, the modulator sites were occupied by two modulator molecules, each with an assigned occupancy of 0.5 and related by a noncrystallographic twofold axis of symmetry. Thus, although it appears from the crystallography that two modulator molecules are superimposed on each other, one dimer interface actually only binds a single modulator.

\section{Modulator-protein interactions: the modulators bind in a dimer-interface, solvent-filled crevice}

The binding site of both modulators is located in a solvent-filled crevice, in the dimer interface, and it is proximal to the transdomain $\beta$-strands that undergo conformational changes during agonist binding and domain closure (Armstrong and Gouaux, 2000). Strikingly, a key element of the modulator binding site involves a $\mathrm{U}$-shaped crevice that is formed by main chain residues Pro 494 through Ser 497, and, as we show subsequently, many of the interactions between the modulators and the receptor are with atoms of the polypeptide main chain, a number of which are mediated by water molecules. Pro 494 forms the apex of the crevice, whereas Ser 497 and 729 define its base.

Two aniracetam molecules have been modeled into the Ani/FW crystal structure and are located on a non crystallographic twofold axis. Aniracetam oxygen atoms $\mathrm{O} 1, \mathrm{O} 2$, and $\mathrm{O} 3$ mediate the primary hydrogen bonding interactions between the modulator and the receptor, as depicted in Figure 4. Atom $\mathrm{O} 2$ forms water-mediated hydrogen bonds with the main chain oxygen atom of Pro A494, the ND2 atom of Asn A754, and the main chain oxygen atom of Ile B481. Both atoms O1 and O2 form water-mediated hydrogen bonds with Lys 730 and Ser 729, except that they interact with different protomers within a dimer, because of their position on a pseudo twofold axis of molecular symmetry. In addition to the hydrogen bonding interactions contributed by the three oxygen atoms, the aromatic ring of aniracetam is involved in nonpolar contacts with the ring of Pro 494. However, in comparing the interactions between the aromatic ring of aniracetam and Pro 494 with those between the
B

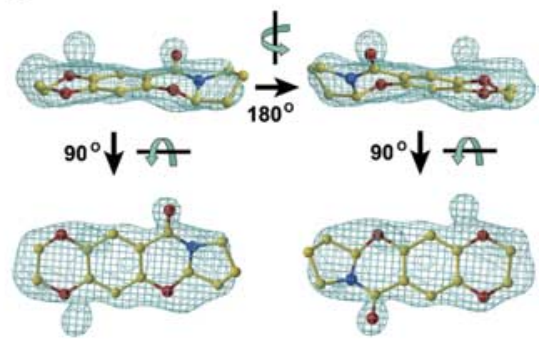

Figure 2. Omit electron density maps calculated using $\left|F_{0}\right|-\left|F_{c}\right|$ coefficients for aniracetam and CX614. A, Electron density for structure to the electron density is shown for each of the twofold related positions of the modulator; on the top rows, the views are

A

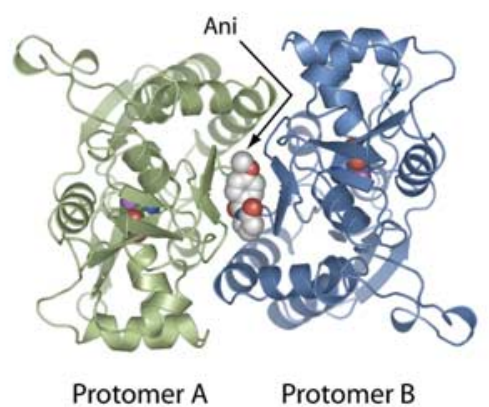

C

Figure 3. Aniracetam and $C X 614$ bind in the dimer interface, in a crevice at the clamshell hinge. $A$, View down the twofold axis, showing the binding of aniracetam, in one of its two equivalent orientations. Protomer $A$ is in green, protomer $B$ is in blue, and Ani/FW complex perpendicular to the molecular twofold axis. Here, aniracetam is red and in CPK representation; the approximate positions of the "linker" that connects the ligand-binding cores to the transmembrane domains is shown. C, View of the CX614 complex, along the molecular twofold axis, with the protein subunits colored as in $A$ and $C X 614$ and quisqualate in CPK representation. $D$, lllustration of CX614 binding pocket using the same view as in $C$, with CX614 in red.

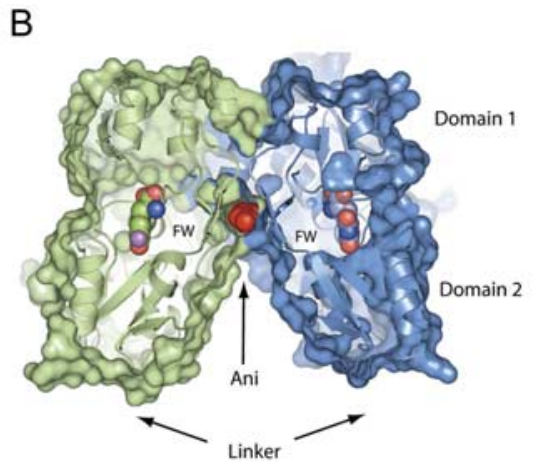

$\mathrm{D}$

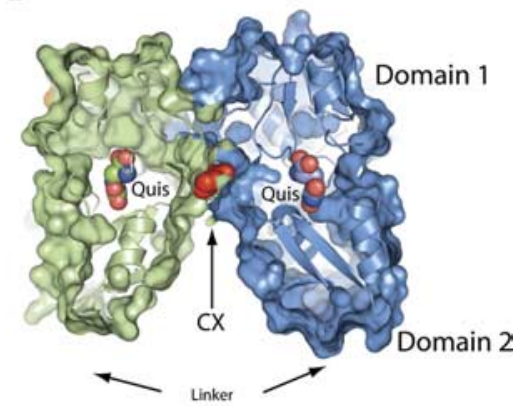

equivalent rings in CX614 and Pro 494, we see that the interactions in the Ani/FW complex are not as extensive.

Six CX614 molecules have been modeled into the CX/Quis crystal structure. For each binding site, two CX614 molecules are modeled that are related by a noncrystallographic twofold axis. The interactions between CX614 and the GluR2 ligand-binding core are identical within experimental uncertainty for all six CX614 molecules. Atoms O2 and O3 of CX614 mediate most of the polar interactions between CX614 and the receptor. Atom O2 participates in a hydrogen bond with the main chain nitrogen atom of Gly 731, located on an interdomain $\beta$-strand near the clamshell "hinge." In addition, four water molecules (W1-W4) 
A

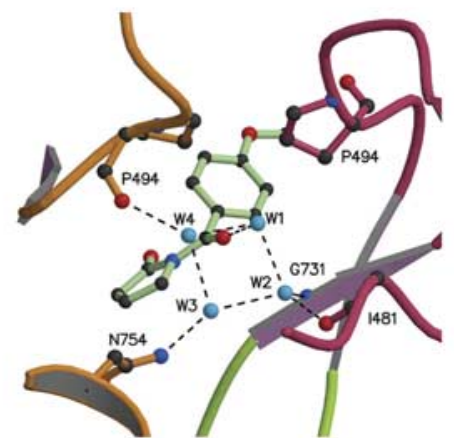

Protomer A Protomer B

C

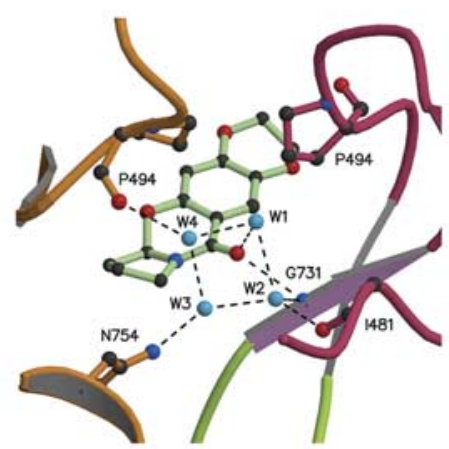

Protomer A Protomer B

E

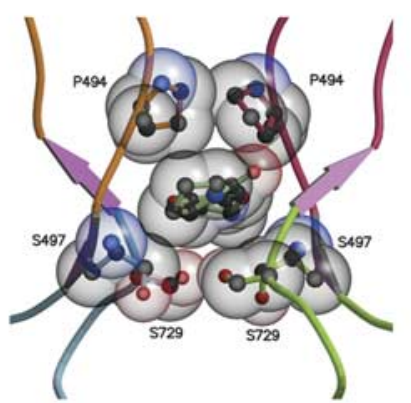

B

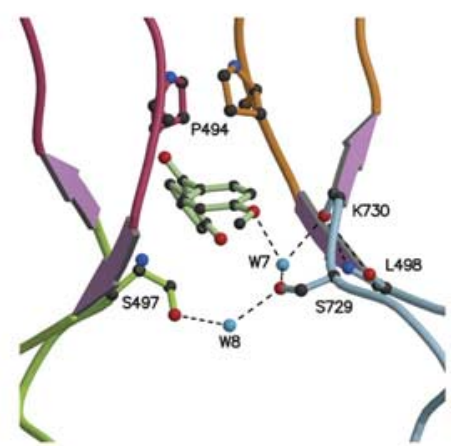

Protomer B Protomer A
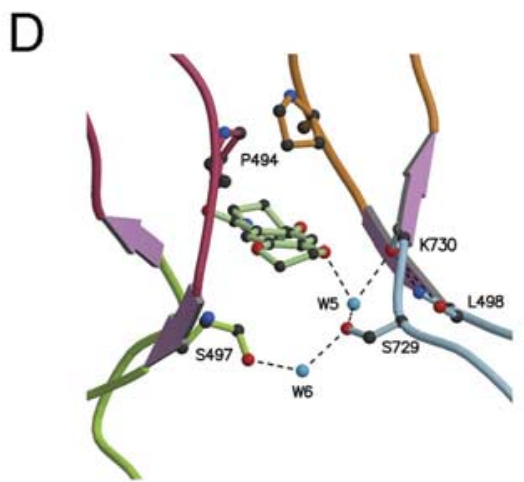

Protomer B Protomer A

oriented approximately parallel to the side chain ring of Pro 494, and the average distance between the two rings is $\sim 5 \AA$. There are additional van der Waals contacts between CX614 and the receptor that include contacts with residues Pro 494-Ser 497 and Ser 729-Gly 731.

The "floor" of the aniracetam and CX614 binding site is formed by four serine residues: two from each subunit Ser 497 and Ser 729, as illustrated in Figure 4. During modulator binding, the side chain of Ser 729 reorients closer to the modulator so that it can participate in a hydrogen bond, whereas the side chain of Ser 497 moves away from the modulator so as to prevent a steric clash. As a consequence of these rearrangements, the four serine residues define a plane that is approximately perpendicular to the molecular twofold axis relating one protein subunit to the other. Indeed, a molecular surface representation of the modulator/GluR2 S1S2 complex shows that the four serine residues seal the floor of the modulator binding site and occlude the modulator from contact with bulk solvent, as seen in Figure 4.

Strikingly, the aniracetam and CX614 molecules bind to essentially the same site in the dimer interface, although they differ substantially in chemical structure. In fact, when a single protomer from the Ani/FW and CX/Quis dimers are superimposed, the resulting positions of the aniracetam and CX614 modulators overlap, as shown in Figure 5. Here we see that specific aromatic rings (Fig. 1, ring 3) of both modulators occupy the same position in the binding site, as does the five-membered, unsaturated ring. Because the nonpolar and polar atoms superimpose almost perfectly, both modulators make similar interactions with protein residues in the dimer interface. This conservation of binding therefore explains why both modulators share the functional behavior of slowing deactivation. Because CX614 has a larger surface area and makes additional polar and nonpolar contacts, it binds more tightly than aniracetam.

\section{Mutation of side chains contacting} modulator impairs modulation

We hypothesized that efficacious allosteric modulation by CX614 was mediated via hydrophobic interactions between the

bridge the $\mathrm{O} 2$ atom of CX614 and oxygen or nitrogen atoms in residues Pro A494, Asn A754, and Ile B481, as illustrated in Figure 4. Atom O3 of CX614 forms a hydrogen bond with the side chain of Ser A729 and the main chain oxygen atom of Lys A730. In addition to polar interactions, the relatively hydrophobic modulators make numerous nonpolar, van der Waals contacts with the receptor. For example, the five-membered ring 1 of CX614 is drug and Pro 494, and hydrogen bonding with the Ser 497 and Ser 729. To test the functional role of these interactions, we mutated each residue individually to alanine and measured deactivation and desensitization kinetics in the absence and presence of CX614 (Fig. 6, Table 3) (supplemental data, available at www. jneurosci.org as supplemental material), focusing on CX614 rather than aniracetam because the effects of CX614 on deactiva- 
tion are more profound. The Ser 497 to Ala (S497A) mutant did not impair modulation, whereas the Ser 729 to Ala (S729A) mutant had a modest effect on modulation of desensitization. We then introduced a larger side chain by mutating the serines to threonines. Modulation was ablated for Ser 497 to Thr (S497T), whereas Ser 729 to Thr (S729T) was indistinguishable from wild type. The functional analyses support our interpretation of the structural data: because the Ser 497 side chain typically moves away from the binding site during modulator binding, making the side chain larger by introducing a threonine, causes steric hindrance between the threonine side chain and CX614, with a resulting loss of modulation. Substituting the S729 side chain with the smaller alanine would make it more difficult for this residue to reorient toward the drug, also resulting in the loss of modulation. The P494A mutation was not functional when assayed in a GluR2 flop background; however, the same mutation in a GluR2 flip background was functional, and, as expected, CX614 modulation was completely lost.

In addition to effects on modulation, mutation of these side chains in some cases altered the intrinsic kinetics of gating (deactivation) and desensitization (Table 3), consistent with a role for hinge domains in channel gating.

Apo state and modulator/agonist-bound state comparison When agonist binds to the GluR2 ligand-binding core, the domain $1 /$ domain 2 clamshell closes by $\sim 21^{\circ}$, enveloping the agonist in the binding cleft. As a consequence of this conformational change, there are substantial changes in the backbone dihedral angles in the $\beta$-strands that link domain 1 and domain 2 and that include residues Ser 497-Ile 500 and Leu 727-Gly 731. Because these residues overlap with the modulator binding site, we wanted to determine the extent to which the modulator binding site changes when agonists bind to the ligand-binding core. To do this, we superimposed the "apo" ligand-binding core and the agonist/modulator-bound ligand-binding core using $\alpha$-carbons in domain 1, a portion of the structure that does change substantially during agonist binding. To our surprise, we found that the modulator binding site is mostly preserved in the agonist-free state, except for the conformation of the side chains of Ser 497 and Ser 729. The side chain of Ser 497 swings out of the binding pocket to make room for the modulators (Fig. 7), whereas the side chain of Ser 729 moves into the binding site to form interactions with the modulators and nearby water molecules.

There is also a small but significant compression of the modulator binding site attributable to the $\sim 1.5 \AA$ movement of main chain atoms of Pro 494, Phe 495, Met 496, and Ser 497 into the pocket during binding of agonist and closure of the clamshell. Shown in Figure 7 are superpositions of apo and agonist bound states, illustrating the movements of side chain and main chain atoms. Thus, in the agonist-bound, closed clamshell state, the modulator binding site is slightly smaller and better matches the chemical structures of aniracetam and CX614. We suggest, therefore, that this is the primary mechanism by which the modulators stabilize the agonist-bound, closed-clamshell state of the receptor.
B

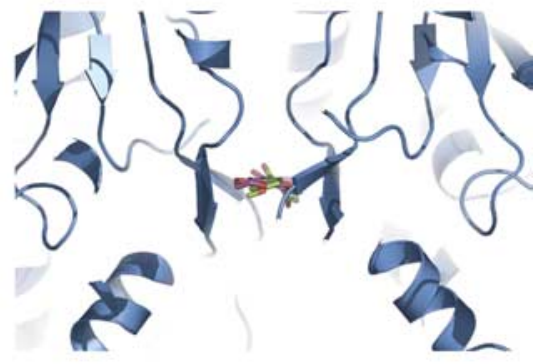

Protomer A
Protomer B

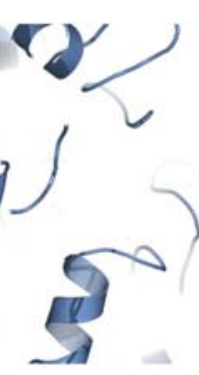

Figure 5. The binding sites of aniracetam and (X614 overlap. $A$, View parallel to the twofold axis showing that aniracetam (green) and CX614 (pink) overlap. In fact, rings 1 and 3 are nearly superimposable. $\boldsymbol{B}$, View perpendicular to the twofold axis, showing that the modulators bind at the same "depth" in the dimer interface.

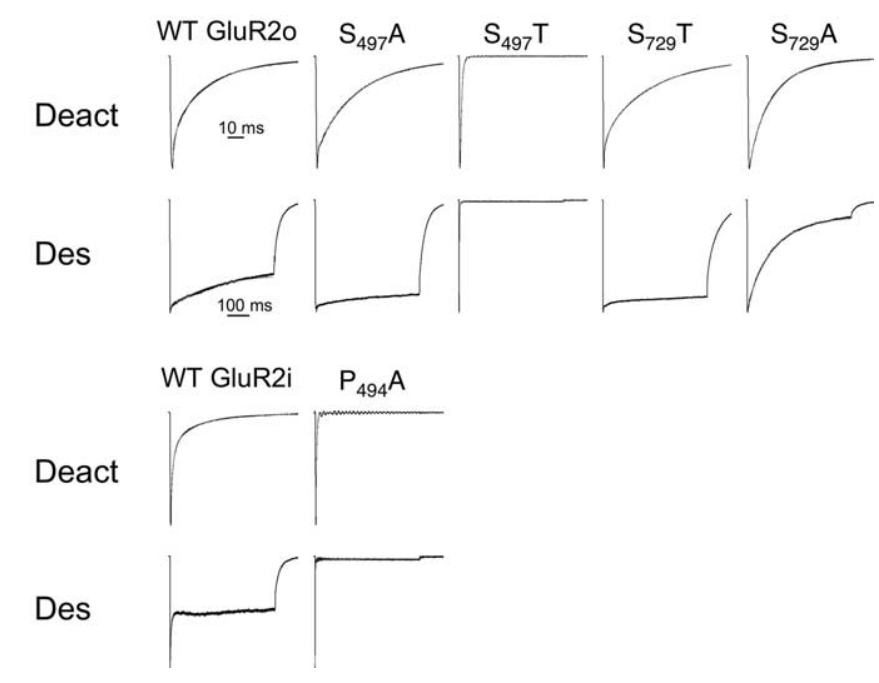

Figure 6. Mutations in modulator binding crevice impair modulation by CX614. Current responses, measured in outside-out patches of transiently transfected HEK 293 cells, of wildtype (WT) GluR2 (flop), and point mutations of residues that interact with CX614 are shown. Top traces show impairment of modulation of deactivation (Deact) by $100 \mu \mathrm{M}$ CX614 with $3 \mathrm{~mm}$ quisqualate; bottom traces show impairment of modulation of desensitization (Des). The P494A mutation was measured in a GluR2 (flip) receptor, because the concomitant mutation in GluR2 (flop) was nonfunctional.

\section{Comparison of the aniracetam/CX614 and cyclothiazide complexes}

Two CTZ molecules bind in the dimer interface, and the two binding sites are related by a molecular twofold axis, as shown in Figure 8. CTZ is oriented such that the long axis of the molecule spans the dimer interface and each end of CTZ interacts extensively, via both polar and nonpolar contacts, to domain 1 and domain 2 on each subunit in the dimer. In contrast, there is only one binding site for aniracetam and CX614, and the binding site is centered on the molecular twofold axis. In addition, the long axes of aniracetam and CX614 are oriented approximately parallel to the dimer interface; the modulators do not penetrate into either domain 1 or domain 2 , and most of the interactions between the modulators and the receptor are nonpolar contacts, with only a few modulator-protein hydrogen bonds.

Structural comparison of the CTZ/Glu, Ani/FW, and CX/ Quis complexes shows that the binding sites for aniracetam and CX614 on the one hand and CTZ on the other hand partially 
Table 3. Effect of mutations on modulation of GluR2 by CX614

\begin{tabular}{|c|c|c|c|c|c|c|c|}
\hline & $\begin{array}{l}\text { Control } \\
\left(\tau_{\text {deact }}\right) \\
\end{array}$ & $\begin{array}{l}\text { Control } \\
\left(\tau_{\text {des }}\right) \\
\end{array}$ & $\begin{array}{l}C X 614 \\
\left(\tau_{\text {deact }}\right) \\
\end{array}$ & $\begin{array}{l}\text { CX614 } \\
\left(\tau_{\text {des }}\right) \\
\end{array}$ & $\begin{array}{l}\text { Fold slowing } \\
\left(\tau_{\text {deact }}\right)\end{array}$ & $\begin{array}{l}\text { Fold slowing } \\
\left(\tau_{\text {des }}\right)\end{array}$ & $\begin{array}{l}\text { \% Des + } \\
\text { CX614 }\end{array}$ \\
\hline WT GluR2(flop) & $\begin{array}{l}0.87 \pm 0.06 \\
(21)\end{array}$ & $\begin{array}{l}1.21 \pm 0.05 \\
(18)\end{array}$ & $\begin{array}{l}23.5 \pm 1.48 \\
(13)\end{array}$ & $\begin{array}{l}207 \pm 28.2 \\
(10)\end{array}$ & 27 & 171 & $37 \pm 4^{d}$ \\
\hline WT GluR2(flip) & $\begin{array}{l}2.52 \pm 0.53 \\
(6)\end{array}$ & $\begin{array}{l}4.76 \pm 0.29 \\
(6)\end{array}$ & $\begin{array}{l}8.91 \pm 1.05 \\
(6)\end{array}$ & & 4 & & $48 \pm 3$ \\
\hline S497A & $\begin{array}{l}1.86 \pm 0.38 \\
(5)^{a}\end{array}$ & $\begin{array}{l}2.60 \pm 0.53 \\
(5)^{a}\end{array}$ & $\begin{array}{l}31.3 \pm 1.68 \\
(6)^{\text {c., }}\end{array}$ & $\begin{array}{l}191 \pm 28.4 \\
(6)\end{array}$ & 17 & 73 & $14 \pm 2$ \\
\hline S497T & $\begin{array}{l}1.03 \pm 0.14 \\
(9)\end{array}$ & $\begin{array}{l}1.34 \pm 0.14 \\
(8)\end{array}$ & $\begin{array}{l}0.87 \pm 0.06 \\
(6)^{c, *}\end{array}$ & $\begin{array}{l}1.32 \pm 0.13 \\
(5)^{\kappa, *}\end{array}$ & 1 & 1 & $89 \pm 3$ \\
\hline S729A & $\begin{array}{l}0.93 \pm 0.08 \\
(10)\end{array}$ & $\begin{array}{l}1.01 \pm 0.06 \\
(8)\end{array}$ & $\begin{array}{l}19.5 \pm 2.21 \\
(6)\end{array}$ & $\begin{array}{l}105 \pm 10.8 \\
(7)^{c, \#}\end{array}$ & 21 & 104 & $77 \pm 5$ \\
\hline S729T & $\begin{array}{l}0.75 \pm 0.04 \\
(5)\end{array}$ & $\begin{array}{l}0.98 \pm 0.02 \\
\text { (4) }\end{array}$ & $\begin{array}{l}25.4 \pm 0.69 \\
(4)\end{array}$ & $\begin{array}{l}330 \pm 62.4 \\
\text { (4) }\end{array}$ & 34 & 337 & $10 \pm 2$ \\
\hline P494A i & $\begin{array}{l}0.37 \pm 0.02 \\
(21)^{b}\end{array}$ & $\begin{array}{l}0.52 \pm 0.03 \\
(28)^{b}\end{array}$ & $\begin{array}{l}0.49 \pm 0.06 \\
(7)\end{array}$ & $\begin{array}{l}0.64 \pm 0.05 \\
(8)\end{array}$ & 1 & 1 & $88 \pm 4$ \\
\hline
\end{tabular}

Mean \pm SEM data for wild-type (WT) and mutant GluR2 receptors. Three functional parameters were measured in the absence and presence of CX614: the time constant of deactivation $\left(\tau_{\text {deact }}\right)$, the time constant of desensitization ( $\tau_{\text {des }}$ ),

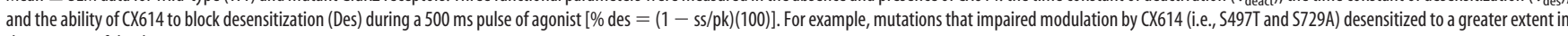
the presence of the drug.

${ }^{a}$ Significantly slower than wild-type control kinetics $(p \leq 0.0001)$.

${ }^{b}$ Significantly faster than wild-type control kinetics ( $\left.p \leq 0.0001\right)$.

'Significantly different from wild-type GluR2o kinetics in the presence of CX614. ${ }^{*} p \leq 0.0001 ; \# \leq 0.01$.

${ }^{d}$ Control percentage desensitization in the absence of drug is $94 \pm 1 \%$.

i, Flop variant was nonfunctional; therefore, flip variant was used.

A

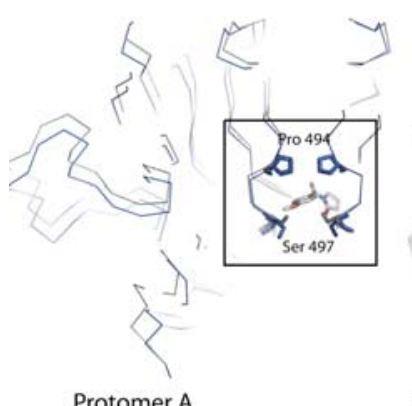

Protomer A
B

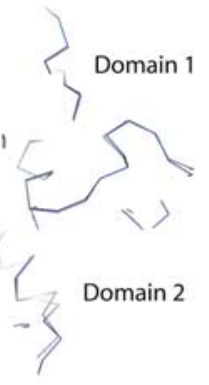

Protomer B

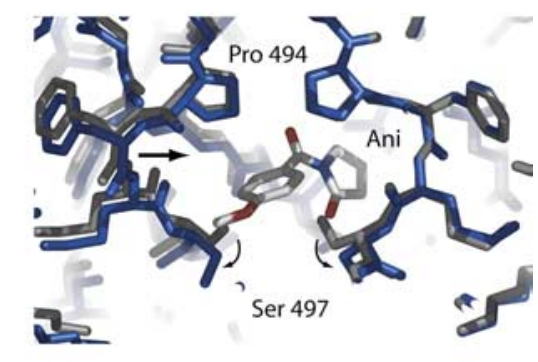

\%

Figure 7. Conformational changes in the modulator binding site during agonist binding and clamshell closure. $\boldsymbol{A}$, Shown here are $\alpha$-carbon traces of the dimers from the Ani/FW complex and the apo state (Armstrong and Gouaux, 2000), in which the domain 1 from protomer $B$ was superposed. In the boxed region, aniracetam is drawn, as are the side chain atoms for Pro 494 and Ser 497. B, Closeup view of the boxed region from $\boldsymbol{A}$. The Ani/FW structure is blue, and the apo structure is gray. During agonist and modulator binding, the main chain atoms of residues Pro 494 -Ser 497 move $\sim 1.5 \AA$ into the modulator binding site.

overlap. Specifically, the binding site for the endocyclic sulfonamide moiety of CTZ, located in the middle of the CTZ molecule, overlaps with the binding sites for the five-membered rings of aniracetam and CX614. In addition, the distal ring 4 of CX614 also overlaps with the endocyclic sulfonamide group of cyclothiazide.

\section{Aniracetam and CX614 promote dimerization of the GluR2 ligand-binding core}

To examine the effect of aniracetam and CX614 on dimerization of the GluR2 ligand-binding core, we performed sedimentation equilibrium experiments in the analytical ultracentrifuge, motivated by the studies of Sun et al. (2002) demonstrating that the dissociation constant of the ligand-binding core dimer was correlated with the extent of receptor desensitization. For CX614, we performed sedimentation equilibrium experiments in the presence and absence of the full agonist AMPA to determine whether the conformation of the clamshell affected the dimer dissociation constant. In both cases, CX614 shifted the dimer-monomer

\section{agonist-bound state}

equilibrium substantially toward dimer. The centrifugation data could be best fit to a two-species, monomer-dimer model, and it yielded experimentally indistinguishable dimer-monomer $K_{\mathrm{d}}$ values of 26.1 $\mu \mathrm{M}$ in the presence of AMPA and 24.1 $\mu \mathrm{M}$ in the apo state. In contrast, aniracetam was less effective at stabilizing the dimer, and the measured dimer to monomer $K_{\mathrm{d}}$ value was $1.4 \mathrm{~mm}$. Although both modulators decrease the dimer $K_{\mathrm{d}}$ value from its value of $\sim 6 \mathrm{mM}$ in the absence of modulator, CX614 stabilizes the dimer to a much greater extent that aniracetam. Shown in Figure 9 are residuals and fits from the sedimentation equilibrium analysis.

\section{Discussion}

Aniracetam and CX614 stabilize the

The clamshell structure of the GluR2 ligand-binding core is composed of two domains that are connected by interdomain $\beta$-strands. The first interdomain $\beta$-strand is composed of Met 496 -Leu 498 ( $\beta 7)$, and the second spans residues Lys 730-Tyr $732(\beta 12)$. Structural analysis shows that the backbone dihedral angles in the regions of Ser 497-Ile 500 and Leu 727-Gly 731, together with the backbone torsion angles of Gly 499 and Lys 730, change significantly during agonist binding (Armstrong and Gouaux, 2000). Correspondingly, the axis that describes the domain closure that occurs during agonist binding runs through the two interdomain $\beta$-strands. Conformational fluctuations in the two interdomain $\beta$-strands is also supported by a recent nuclear magnetic resonance (NMR) study that showed that residues Leu 498, Gly 499, Leu 727, and Glu 728 exhibit chemical exchange (McFeeters and Oswald, 2002). Together, the crystallographic and NMR data reinforce the notion that regions Met 496-Ile 500 and Leu 727-Tyr 732 undergo conformational changes during 
agonist binding. This region, therefore, is referred to as the interdomain hinge.

Among the six residues that make hydrogen bonding or van der Waals contacts with aniracetam and CX614, four are located in the interdomain hinge (Ser 497, Ser 729, Gly 731, and Lys 730). By binding to the hinge region, aniracetam and CX614 may stabilize the closed-cleft, agonist-bound conformation of the ligand-binding core. By stabilizing the closed-cleft, agonist-bound conformation, the modulators slow agonist unbinding and therefore ion channel deactivation, consistent with an increase in $P_{\mathrm{o}}$ in the presence of aniracetam (Lawrence et al., 2003). Destabilizing the closed-cleft conformation has the opposite effect, increasing the rate of channel deactivation (Robert et al., 2005).

\section{Aniracetam and CX614 stabilize the ligand-binding core dimer}

Sedimentation equilibrium experiments show that CX614 lowers the GluR2 S1S2 dimer $K_{\mathrm{d}}$ from $\sim 6 \mathrm{mM}$ to $26.1 \mu \mathrm{M}$. CTZ more effectively stabilizes the dimer, and, in the presence of saturating CTZ, the dimer $K_{\mathrm{d}}$ is $1.2 \mu \mathrm{M}$ (Sun et al., 2002). In contrast, aniracetam provides minimal stabilization to the dimer and only lowers the dimer $K_{\mathrm{d}}$ to $\sim 1.4 \mathrm{~mm}$, although because of the limited solubility of aniracetam, we may not have saturated the binding site. Because stabilization of the dimer interface decreases the extent of receptor desensitization (Sun et al., 2002), we suggest that the effects that aniracetam and CX614 have on diminishing the rate of receptor desensitization are attributable to the degree to which they stabilize the dimer interface. We suggest, therefore, that the structural underpinning of receptor desensitization and deactivation are conceptually separable: stabilization of the dimer interface primarily affects receptor desensitization, whereas stabilization of the closed-clamshell state of the ligand-binding core slows deactivation. Although this model is appealing, it is an oversimplification because it does not explain why the L483Y mutation, which is relatively far from the interdomain hinge, slows receptor deactivation by $\sim 10$-fold (Sun et al., 2002). Furthermore, although CTZ and CX614 primarily effect desensitization and deactivation, respectively, CTZ also slows deactivation and CX614 slows desensitization. The inseparability of modulation of deactivation and desensitization arises because the interdomain hinges are located at the dimer interface (Partin et al., 1996; Lawrence et al., 2003). We suggest that these overlapping functional activities are attributable to the fact that the binding sites for these modulators partially overlap. Additional functional and structural experiments will be required to unravel the relationships between deactivation and desensitization.

\section{Modulator binding is sensitive to functional states of the receptor}

A striking feature of compounds such as aniracetam and CX614 is that they selectively modulate one functional state of a complex receptor that occupies many functional states. Indeed, recent

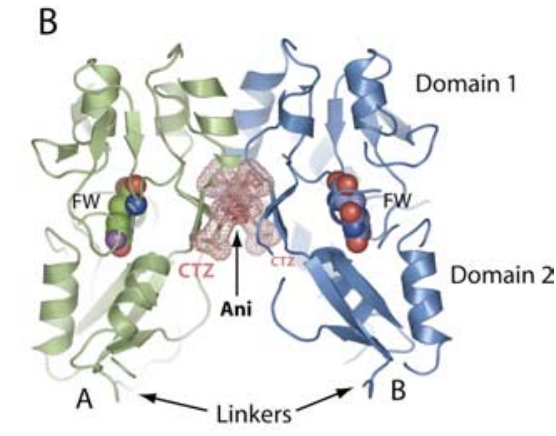

D
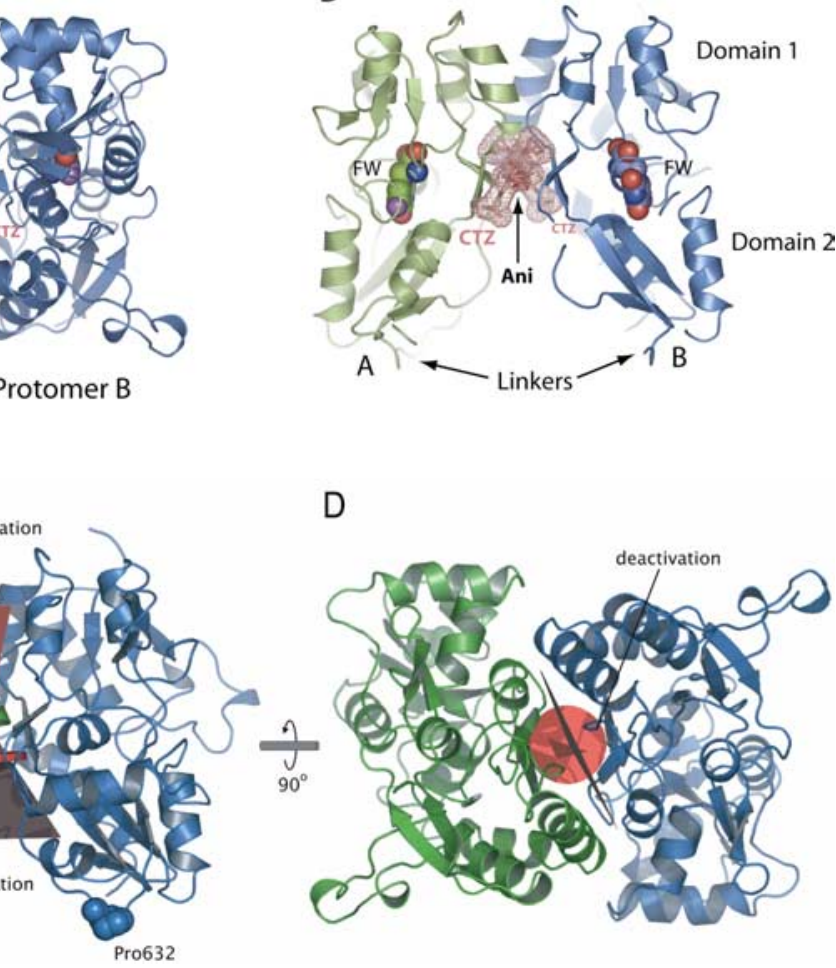

Figure 8. Comparison of the binding sites for aniracetam and CTZ. A, View down the twofold axis of the Ani/FW complex, hinges between domains I and II (red circle). Rotating the view by $90^{\circ}(\boldsymbol{D})$ allows a view of the CX614 interaction with the hinges, resulting in modulation of deactivation by stabilizing the closed-clamshell conformation.

electrophysiological studies using intact AMPA receptors and a related compound, 1-(1,4-benzodioxan-6-ylcarbonyl) piperidine (CX546), suggest that the modulator binds preferentially to the agonist-bound, nondesensitized state of the receptor, i.e., to the activated state (Nagarajan et al., 2001). Although we do not see large differences between the aniracetam and CX614 binding sites in the apo and agonist-bound states of the ligand-binding core, there is a compression of the modulator binding site and rearrangements of side chains and water molecules that accompany modulator binding. Because the ligand-binding core interface rearranges during receptor desensitization and the modulator binding site is situated in the middle of the nondesensitized dimer interface, dimer interface rearrangement during receptor desensitization will split the modulator binding site in half, thereby completely disrupting it.

\section{Modulator pharmacology}

Aniracetam, a weak binding modulator with an $\mathrm{EC}_{50}$ of $>5 \mathrm{mM}$, was the lead compound for the development of the AMPAkine series of modulators (Tang et al., 1991). The early AMPAkine molecules, with potencies in the high micromolar range, were similar in architecture to aniracetam and contained two separate ring structures connected by a carbonyl group, with representative members being 1-(1,3-benzodioxol-5-ylcarbonyl)piperidine (BDP; CX465), 1-(quinoxalin-6-ylcarbonyl)piperidine (BDP-12; CX516), and CX546 (Arai et al., 1994, 1996b). A more recent generation of AMPAkines has two rings structures connected by 
A
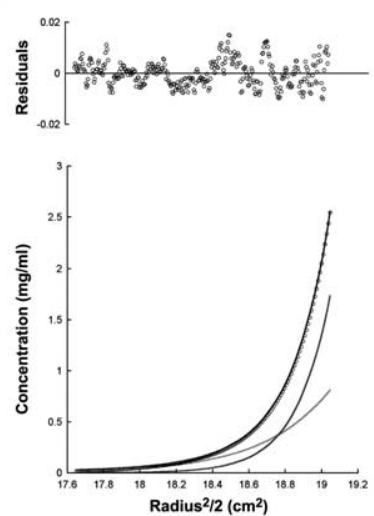

B

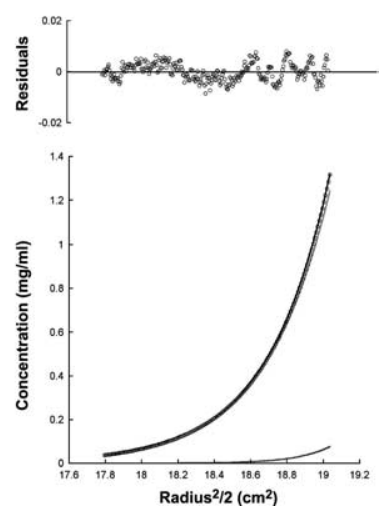

Figure 9. Sedimentation equilibrium data showing that CX614 and aniracetam stabilize the GluR2 dimer to different extents. $\boldsymbol{A}$, Sedimentation equilibrium data taken in the presence of 0.3 mM AMPA and $0.3 \mathrm{~mm}$ CX614; the data shown here was collected at $27 \mathrm{~K} \mathrm{rpm}$ and a protein concentration of $1.0 \mathrm{mg} / \mathrm{ml}$. $\boldsymbol{B}$, Sedimentation equilibrium data measured in the presence of 2 $\mathrm{mm}$ glutamate and $5 \mathrm{~mm}$ aniracetam. For the data shown here, the rotor speed was also $27 \mathrm{~K}$ $\mathrm{rpm}$, and the loading protein concentration was $0.75 \mathrm{mg} / \mathrm{ml}$. In both of the experiments involving CX614 and aniracetam, interference data from three loading protein concentrations and three rotor speeds were fit to a dimer-monomer equilibrium, yielding a protein dimer $K_{d}$ of 26.1 $\mu m$ in the case of $C X 614$ and $1.4 \mathrm{~mm}$ for aniracetam. In $\boldsymbol{A}$ and $\boldsymbol{B}$, the top panels show the residuals of the fit of the dimer-monomer model to the measured interference data, and the bottom panels show the measured interference data (open black circles), the fit to the data (solid black line), and the relative predicted concentrations of dimer (dark gray line) and monomer (light gray line). As seen in $\boldsymbol{A}$, CX614 is much more effective in shifting the dimer-monomer toward dimer than aniracetam.

a fused six-atom heterocyclic ring, with representative examples being 1-(1,3-benzodioxol-5-ylcarbonyl)piperidine-20 (BDP-20; CX554) and CX614. On the basis of physiological and behavioral experiments, CX554 has a potency approximately an order of magnitude lower than the previous $\mathrm{BDP}$ compounds $\left(\mathrm{EC}_{50}\right.$ of $\sim 300 \mu \mathrm{M}$ ) (Arai et al., 1996a), whereas CX614 is more potent, with an $\mathrm{EC}_{50}$ of 20-40 $\mu \mathrm{M}$ (Arai et al., 2000). More recently, high-affinity modulators, such as LY404187, have been shown to modulate desensitization and appear to bind in the dimer interface (Quirk and Nisenbaum, 2003).

Because aniracetam and CX614 are representative of the weakest and most potent drugs in this series, respectively, the structures of their complexes with the GluR2 ligand-binding core provide a unique opportunity to investigate structure and function relationships. In general, the binding of aniracetam and CX614 is driven primarily by nonpolar, van der Waals contacts, the hydrophobic effect, and, to a lesser extent, hydrogen bonds. The modulator binding site, before modulator binding, is preorganized and filled with ordered solvent. Both aniracetam and CX614 are relatively hydrophobic molecules and have few polar atoms. Perhaps the most significant difference between aniracetam and CX614, however, is that CX614 is a substantially more rigid, constrained molecule. On the basis of the aniracetam structure, the planes of the two rings are staggered by $\sim 60^{\circ}$. By joining rings 1 and 3, as in the case of CX614, the orientation of rings 1 and 3 are covalently constrained to a relative orientation that is favorable for binding. The conformational rigidity of the molecules may contribute to high potency by maximizing interactions with the receptors while minimizing unfavorable entropy loss during modulator binding. Modulator rigidity may also contribute to high potency by enabling optimal nonpolar contacts between ring 1 and Pro 494, and hydrogen bonding interactions involving $\mathrm{O} 2$ and $\mathrm{O} 3$.

The cocrystal structure with CX614 can also help to answer questions of structure and function relationships in other modulators, such as why CX614 is more potent than CX554, although they have nearly identical structures. Indeed, the only difference between CX614 and CX554 is that the two oxygen atoms extending from the benzene ring are connected by two methylene groups in CX614 and a single methylene group in CX554. In the CX614 structure, ring 4 is located in a hydrophobic pocket defined by residues Pro 494, Val 750, Leu 751, and Leu 759. Because CX614 has an additional methylene group, it can better fill the hydrophobic pocket and, in so doing, can also participate in additional van der Waals contacts. The slightly greater hydrophobicity of CX614 will also enhance binding.

A common feature of modulator binding in the dimer interface is the displacement of ordered water molecules. For example, before modulator binding, the aniracetam and CX614 binding sites are occupied by eight ordered water molecules, and, after the modulators bind, all eight water molecules are displaced; the hydrophobic pocket that is occupied by the bicyclic ring of CTZ is filled with four water molecules before CTZ binding, and similarly, these four waters are displaced during CTZ binding. In the Ani/FW and CX/Quis complexes, there is an ordered water molecule that mimics one of the oxygen atoms of the 7-sulfonamide group of CTZ.

\section{Conclusions}

The crystal structures of the GluR2 ligand-binding core Ani/FW and CX/Quis complexes reveal a new binding site for positive allosteric modulators of AMPA receptors. This binding site is located in the dimer interface and at the interdomain hinge. We suggest that aniracetam and CX614 stabilize the ligand-binding core in the agonist-bound, activated state, thereby slowing agonist release and ion channel deactivation. Aniracetam and CX614 also stabilize the ligand-binding core dimer and, through this effect, reduce the rate of receptor desensitization. The high resolution crystal structures presented here demonstrate, for the first time, how modulators can differentially affect deactivation and desensitization, they lend insight into the mechanism underlying modulator potency and efficacy, and they provide a structural basis from which to design a new generation of AMPA receptor modulators.

\section{References}

Arai A, Lynch G (1998) The waveform of synaptic transmission at hippocampal synapses is not determined by AMPA receptor desensitization. Brain Res 799:230-234.

Arai A, Kessler M, Xiao P, Ambros-Ingerson J, Rogers G, Lynch G (1994) A centrally active drug that modulates AMPA receptor gated currents. Brain Res 638:343-346.

Arai A, Kessler M, Ambros-Ingerson J, Quan A, Yigiter E, Rogers G, Lynch G (1996a) Effects of a centrally active benzoylpyrrolidine drug on AMPA receptors kinetics. Neuroscience 75:573-585.

Arai A, Kessler M, Rogers G, Lynch G (1996b) Effects of a memory-enhancing drug on D,L-alpha-amino-3-hydroxy-5-methyl-4-isoxazolepropionic acid receptor currents and synaptic transmission in hippocampus. J Pharmacol Exp Ther 278:627-638.

Arai AC, Kessler M, Rogers G, Lynch G (2000) Effects of the potent ampakine CX614 on hippocampal and recombinant AMPA receptors: interactions with cyclothiazide and GYKI 52466. Mol Pharmacol 58:802-813.

Armstrong N, Gouaux E (2000) Mechanisms for activation and antagonism of an AMPA-sensitive glutamate receptor: crystal structures of the GluR2 ligand binding core. Neuron 28:165-181.

Boulter J, Hollmann M, O’Shea-Greenfield A, Hartley M, Deneris E, Maron C, Heinemann S (1990) Molecular cloning and functional expression of glutamate receptor subunit genes. Science 249:1033-1037. 
Brünger AT (1992) Free $R$ value: a novel statistical quantity for assessing the accuracy of crystal structures. Nature 355:472-475.

Brünger AT, Adams PD, Clore GM, DeLano WL, Gros P, Grosse-Kunstleve RW, Jiang JS, Kuszewski J, Nilges M, Pannu NS, Read RJ, Rice LM, Simonson T, Warren GL (1998) Crystallography and NMR system: a new software suite for macromolecular structure determination. Acta Crystallogr D Biol Crystallogr 54:905-921.

Chen GQ, Gouaux E (1997) Overexpression of a glutamate receptor (GluR2) ligand binding domain in Escherichia coli: application of a novel protein folding screen. Proc Natl Acad Sci USA 94:13431-13436.

Delano WL (2005) The PyMOL molecular graphics system. San Carlos, CA: DeLano Scientific.

Dingledine R, Borges K, Bowie D, Traynelis SF (1999) The glutamate receptor ion channels. Pharmacol Rev 51:7-61.

Esnouf RM (1999) Further additions to MolScript version 1.4, including reading and contouring of electron density maps. Acta Crystallogr D Biol Crystallogr 55:938-940.

Fleck MW, Cornell E, Mah SJ (2003) Amino-acid residues involved in glutamate receptor 6 kainate receptor gating and desensitization. J Neurosci 23:1219-1227.

Horning M, Mayer M (2004) Regulation of AMPA receptor gating by ligand binding core dimers. Neuron 41:379-388.

Ingvar M, Ambros-Ingerson J, Davis M, Granger R, Kessler M, Rogers GA, Schehr RS, Lynch G (1997) Enhancement by an ampakine of memory encoding in humans. Exp Neurol 146:553-559.

Isaacson JS, Nicoll RA (1991) Aniracetam reduces glutamate receptor desensitization and slows the decay of fast excitatory synaptic currents in the hippocampus. Proc Natl Acad Sci USA 88:10936-10940.

Jin R, Gouaux E (2003) Probing the function, conformational plasticity and dimer-dimer contacts of the GluR2 ligand-binding core: studies of 5-substituted willardiines and GluR2 S1S2 in the crystal. Biochemistry 42:5201-5213.

Jin R, Horning M, Mayer ML, Gouaux E (2002) Mechanism of activation and selectivity in a ligand-gated ion channel: structural and functional studies of GluR2 and quisqualate. Biochemistry 41:15635-15643.

Jin R, Banke T, Mayer ML, Traynelis SF, Gouaux E (2003) Structural basis for partial agonist action at ionotropic glutamate receptors. Nat Neurosci 6:803-810

Jones TA, Kjeldgaard M (1997) Electron-density map interpretation. Methods Enzymol 277:173-208.

Jones TA, Zou JY, Cowan SW (1991) Improved methods for building protein models in electron density maps and the location of errors in these models. Acta Crystallogr A 47:110-119.

Kandel ER (2001) The molecular biology of memory storage: a dialogue between genes and synapses. Science 294:1030-1038.

Keinänen K, Wisden W, Sommer B, Werner P, Herb A, Verdoorn TA, Sakmann B, Seeburg PH (1990) A family of AMPA-selective glutamate receptors. Science 249:556-560.

Kleywegt GJ (1999) Experimental assessment of differences between related protein crystal structures. Acta Crystallogr D Biol Crystallogr 55:1878-1884.

Kraulis PJ (1991) MOLSCRIPT: a program to produce both detailed and schematic plots of protein structures. J Appl Cryst 24:946-950.

Lawrence JJ, Brenowitz S, Trussell LO (2003) The mechanism of action of aniracetam at synaptic $\alpha$-amino-3-hydroxy-5-methyl-4-isoxazolepropionic acid (AMPA) receptors: indirect and direct effects on desensitization. Mol Pharmacol 64:269-278.

Leever JD, Clark S, Weeks AM, Partin KM (2003) Identification of a site in GluR1 and GluR2 that is important for modulation of deactivation and desensitization. Mol Pharmacol 64:5-10.

Mayer ML, Armstrong N (2004) Structure and function of glutamate receptor ion channels. Annu Rev Physiol 66:161-181.

McFeeters RL, Oswald RE (2002) Structural mobility of the extracellular ligand-binding core of an ionotropic glutamate receptor. Analysis of NMR relaxation dynamics. Biochemistry 41:10472-10481.

Merritt EA, Murphy MEP (1994) Raster3D, version 2.0. A program for photorealistic molecular graphics. Acta Crystallogr D Biol Crystallogr 50:869-873.

Miu P, Jarvie KR, Radhakrishnan V, Gates MR, Ogden A, Ornstein PL, Zarrinmayeh H, Ho K, Peters D, Grabell J, Gupta A, Zimmerman DM, Bleakman D (2001) Novel AMPA receptor potentiators LY392098 and LY404187: effects on recombinant human AMPA receptors in vitro. Neuropharmacology 40:976-983.

Morris RG, Anderson E, Lynch GS, Baudry M (1986) Selective impairment of learning and blockage of long-term potentiation by an $N$-methyl-Daspartate receptor antagonist, AP5. Nature 319:774-776.

Nagarajan N, Quast C, Boxall AR, Shahid M, Rosenmund C (2001) Mechanism and impact of allosteric AMPA receptor modulation by the ampakine CX546. Neuropharmacology 41:650-663.

Navaza J (1994) AMoRe: an automated package for molecular replacement. Acta Crystallogr A 50:157-163.

O’Neill MJ, Bleakman D, Zimmerman DM, Nisenbaum ES (2004) AMPA receptor potentiators for the treatment of CNS disorders. Curr Drug Targets 3:181-194.

Partin KM, Fleck MW, Mayer ML (1996) AMPA receptor flip/flop mutants affecting deactivation, desensitization, and modulation by cyclothiazide, aniracetam, and thiocyanate. J Neurosci 16:6634-6647.

Quirk JC, Nisenbaum ES (2003) Multiple molecular determinants for allosteric modulation of alternatively spliced AMPA receptors. J Neurosci 23:10953-10962.

Rammsayer TH (2001) Effects of pharmacologically induced changes in NMDA-receptor activity on long-term memory in humans. Learn Mem $8: 20-25$.

Robert A, Armstrong N, Gouaux E, Howe JR (2005) AMPA receptor binding cleft mutations that alter affinity, efficacy, and recovery from desensitization. J Neurosci 25:3752-3762.

Sun Y, Olson RA, Horning M, Armstrong N, Mayer ML, Gouaux E (2002) Mechanism of glutamate receptor desensitization. Nature 417:245-253.

Tang CM, Shi QY, Katchman A, Lynch G (1991) Modulation of the time course of fast EPSCs and glutamate channel kinetics by aniracetam. Science 254:288-290.

Tsien JZ, Huerta PT, Tonegawa S (1996) The essential role of hippocampal CA1 NMDA receptor-dependent synaptic plasticity in spatial memory. Cell 87:1327-1338.

van Aalten DM, Bywater R, Findlay JB, Hendlich M, Hooft RW, Vriend G (1996) PRODRG, a program for generating molecular topologies and unique molecular descriptors from coordinates of small molecules. J Comput Aided Mol Des 10:255-262.

Vyklicky LJ, Patneau DK, Mayer ML (1991) Modulation of excitatory synaptic transmission by drugs that reduce desensitization at AMPA/kainate receptors. Neuron 7:971-984. 